\title{
Steatotic Rat Hepatocytes in Primary Culture Are More Susceptible to the Acute Toxic Effect of Acetaminophen
}

\author{
O. KUČERA ${ }^{1}$, S. AL-DURY ${ }^{1}$, H. LOTKOVÁ ${ }^{1}$, T. ROUŠAR $^{1,2}$, D. RYCHTRMOC ${ }^{1}$, \\ Z. ČERVINKOVÁ ${ }^{1}$
}

${ }^{1}$ Department of Physiology, Faculty of Medicine in Hradec Králové, Charles University in Prague, Hradec Králové, Czech Republic, ${ }^{2}$ Department of Biological and Biochemical Sciences, Faculty of Chemical Technology, University of Pardubice, Pardubice, Czech Republic

Received March 20, 2012

Accepted May 24, 2012

\section{Summary}

Acetaminophen (APAP) overdose is the most common cause of acute liver failure in humans. Non-alcoholic fatty liver disease is the most frequent chronic liver disease in developed countries. The aim of our work was to compare the effect of APAP on intact rat hepatocytes and hepatocytes isolated from steatotic liver in primary cultures. Male Wistar rats were fed with standard diet (10\% energy from fat) and high-fat diet (71 \% energy from fat) for 6 weeks and then hepatocytes were isolated. After cell attachment, $\operatorname{APAP}(1 ; 2.5 ; 3.75$ and $5 \mathrm{mM})$ was added to culture media (William's E medium) and hepatocytes were cultured for up to 24 hours. APAP caused more severe dose-dependent damage of steatotic hepatocytes as documented by increased release of lactate dehydrogenase (LDH) and LDH leakage, decreased activity of cellular dehydrogenases (WST-1 test) and reduced albumin production. Intact steatotic hepatocytes contained lower amount of reduced glutathione (GSH). Treatment with APAP (1 and $2.5 \mathrm{mmol} / \mathrm{l}$ ) caused more pronounced decrease in GSH in steatotic hepatocytes. ROS (reactive oxygen species) formation after 24-hour incubation was significantly higher in fatty hepatocytes using APAP at concentration of 3.75 and $5 \mathrm{mmol} / \mathrm{l}$. Interleukin 6 (IL-6) production was elevated in $2.5 \mathrm{mM}$ APAP-treated nonsteatotic and steatotic hepatocyte cultures at 8 hours, compared to appropriate controls. In conclusions, our results indicate that steatotic hepatocytes exert higher sensitivity to the toxic action of APAP. This sensitivity may be caused by lower content of GSH in intact steatotic hepatocytes and by more pronounced APAPinduced decrease in intracellular concentration of GSH.

\section{Key words}

Fatty liver - Acetaminophen • Hepatocytes in vitro • Hepatotoxicity • Glutathione

\section{Corresponding author}

Otto Kučera, Charles University in Prague, Faculty of Medicine in Hradec Králové, Department of Physiology, Šimkova 870, 50038 Hradec Králové, Czech Republic. Fax: +420 495518772. E-mail: kucerao@Ifhk.cuni.cz

\section{Introduction}

Non-alcoholic fatty liver disease (NAFLD) is the most frequent chronic liver disease in the developed countries (Bedogni et al. 2005). Histological picture of NAFLD ranges from simple steatosis to non-alcoholic steatohepatitis. While simple steatosis is thought to be a benign hepatic manifestation of metabolic syndrome, steatohepatitis may subsequently progress to liver cirrhosis which can lead to the development of hepatocellular carcinoma. Simple fatty liver is the most common form of NAFLD and may affect $20-30 \%$ of adult population in the western countries (Vernon et al. 2011). Although simple steatosis usually does not cause severe clinical symptoms, it exerts some alterations in mitochondrial function (Vendemiale et al. 2001, Kučera et al. 2011a), higher formation of reactive oxygen species (ROS) (Videla et al. 2004), lower content of reduced glutathione (GSH) (Gambino et al. 2011), induction of cytochrome P450 2E1 (Orellana et al. 2006) and cytokine imbalance (Braunersreuther et al. 2012). All these conditions are suspected of increasing sensitivity of the 
liver to hepatotoxicity.

Acetaminophen (APAP) is widely used analgesic and antipyretic and is safe when used within pharmacological doses. Nevertheless, APAP overdose is the leading cause of acute liver failure in the USA (Lee 2003). At therapeutic doses, APAP is preferentially metabolized by conjugation with glucuronate and sulphate to non-toxic metabolites and only small fraction of APAP is biotransformed by cytochrome P450 dependent oxidase enzyme system to N-acetyl-pbenzoquinone imine (NAPQI) (Dahlin et al. 1984) which is detoxified by conjugation with reduced glutathione (GSH) to form APAP-SG conjugate (Rollins and Buckpitt 1979).

The toxicity of APAP in overdose has been shown to be initiated by increased formation of NAPQI which induces depletion of GSH (Mitchell et al. 1973), impairment of mitochondrial respiration (Vendemiale et al. 1996), increased formation of ROS (Bajt et al. 2004, Roušar et al. 2009), opening of mitochondrial permeability transition pore (Kon et al. 2004), and Kupffer cell activation (Ju et al. 2002). A novel possible mechanism of toxic action of APAP and its metabolite APAP-SG has been described recently (Roušar et al. 2010).

We have already proven higher hepatotoxicity of APAP in steatotic rat liver in vivo (Kučera et al. 2012) but the precise mechanism, by which fatty liver predisposes to increased toxicity of APAP, still remains unclear. To study the detailed mechanisms of toxic liver injury, model systems in vitro are favourably used. The aim of our work was to compare sensitivity of nonsteatotic hepatocytes and steatotic hepatocytes in primary culture to acute toxic effect of APAP and to try to reveal detailed mechanisms of higher susceptibility of fatty hepatocytes to toxicity of APAP.

\section{Material and Methods}

\section{Chemicals}

Medium William's E (without phenol red), fetal bovine serum, penicillin, streptomycin and glutamine were purchased from PAN BIOTECH GmbH (Germany). Collagenase (Collagenase NB 4 Standard Grade from Clostridium histolyticum) was obtained from Biotech (Czech Republic), insulin (Actrapid, Hoechst, Germany), glucagon (Novo Nordisk, Denmark), prednisolon (SoluDecortin, Merck, USA), Rat Albumin ELISA Quantification Kit (Bethyl Lab. Inc., USA), and Cell Proliferation Reagent WST-1 (Roche, Germany) were from the suppliers mentioned in brackets. Type I collagen, trypan blue, acetaminophen, and all other chemicals were purchased from Sigma-Aldrich (USA).

\section{Animals}

Male albino Wistar rats (Biotest, Czech Republic) were housed at $23 \pm 1{ }^{\circ} \mathrm{C}, 55 \pm 10 \%$ relative humidity, air exchange 12-14 times/h, and 12-h light-dark cycle periods $(6: 00 \mathrm{~h}$ to $18: 00 \mathrm{~h})$. Rats used for isolation of nonsteatotic hepatocytes were fed ad libitum a standard pelleted diet (ST-1, Velaz, Prague, Czech Republic; $10 \%$ energy fat, $30 \%$ energy proteins, $60 \%$ energy saccharides) for 6 weeks. For isolation of fatty hepatocytes, animals were fed slightly modified high-fat gelled diet (HFGD; $71 \%$ energy fat, $18 \%$ energy proteins, $11 \%$ energy saccharides) according to Lieber et al. (2004) for 6 weeks. The animals had free access to tap water. All animals received care according to the guidelines set by the Institutional Animal Use and Care Committee of the Charles University, Prague, Czech Republic.

\section{Hepatocyte isolation, cultivation and treatment}

Hepatocytes were isolated from rats by collagenase perfusion (Berry et al. 1991). The viability of freshly isolated hepatocytes used in experiments was more than $90 \%$ as confirmed by trypan blue exclusion test. Isolated hepatocytes were suspended in William's E medium supplemented with foetal bovine serum (6\%), glutamine $(2 \mathrm{mmo} / \mathrm{l})$, penicillin $(100 \mathrm{IU} / \mathrm{ml})$, streptomycin $(10 \mathrm{mg} / \mathrm{ml})$, insulin $(0.08 \mathrm{IU} / \mathrm{ml})$, prednisolon $(0.5 \mathrm{lg} / \mathrm{ml})$, glucagon $(0.008 \mathrm{lg} / \mathrm{ml})$ and plated in collagen-coated Petri dishes $(60 \mathrm{~mm})$ or 12-, 24and 96- well plates at a density of 70,000 cells $/ \mathrm{cm}^{2}$. Hepatocytes were allowed to attach in a gassed atmosphere $\left(5 \% \mathrm{CO}_{2}\right)$ at $37{ }^{\circ} \mathrm{C}$ for $2 \mathrm{~h}$. After the establishment of monolayers, the medium was removed and replaced with a fresh supplemented medium without foetal bovine serum containing dissolved acetaminophen at concentrations of $1 ; 2.5 ; 3.75$ and $5 \mathrm{mmol} / 1$. Control hepatocytes were incubated in William's E medium without APAP. The treatment period lasted up to 24 hours $\left(5 \% \mathrm{CO}_{2}, 37{ }^{\circ} \mathrm{C}\right)$. Then the medium and cells were collected for the required assays.

\section{Biochemical assays}

Hepatocyte toxicity was determined by the activity of lactate dehydrogenase (LDH) in the culture medium and by LDH leakage. LDH activity in the culture 
medium and in lysate of hepatocytes (frozen and lysed cells in distilled water) was measured using a commercial kit from DiaSys (Germany). To evaluate the functional capacity of cultured hepatocytes the amount of albumin secreted into the culture medium during the incubation was measured using the ELISA kit from Bethyl Lab. Inc., USA. Cell viability was also evaluated by the WST-1 assay (Roche, Germany). The WST-1 test measures the activity of cellular dehydrogenases (Lotková et al. 2009). After cell lysis in a freezer $\left(-80{ }^{\circ} \mathrm{C}, 10 \mathrm{~min}\right)$ and the harvesting of hepatocytes, the antioxidative status of the hepatocytes was determined by spectrofluorometric assay for reduced glutathione based on the reaction between glutathione and o-phthalaldehyde $(\lambda(\mathrm{exc})=340 \mathrm{~nm}$, pH 6.0) (Roušar et al. 2012). The production of ROS was evaluated using 5- and 6-chloromethyl-2',7'-dichlorodihydrofluorescein diacetate $\left(\mathrm{CM}-\mathrm{H}_{2} \mathrm{DCFDA} ; 1 \mu \mathrm{M}\right.$; Molecular Probes, USA). Slightly modified method was previously described (Roušar et al. 2009). The results are expressed in a percentage where "lean" intact hepatocytes exerted $100 \%$ fluorescence (difference in fluorescence intensity at the end and at the beginning of a measurement). Concentrations of interleukin 6 (IL-6) in culture medium was measured by enzyme linked immunosorbent assay (ELISA) according to manufacturer's instructions (BMS625, Bender MedSystems, Vienna, Austria).

\section{Statistical analysis}

Experiments were repeated at least three times using different isolations of hepatocytes. The results are expressed as a mean $\pm \mathrm{SD}$. After testing the normality, the statistical significance was analysed using the oneway ANOVA test followed by Tukey-Kramer's post hoc test for comparing the control group to the others. (GraphPad Prism 4.03 for Windows, GraphPad Software, USA). $\mathrm{p}<0.05$ was considered to be statistically significant.

\section{Results}

Figure 1A shows time course of LDH activity in culture medium. Data up to 5.5-hour incubation are not presented because we did not observe any differences among groups. Significantly higher activity of LDH in medium of control steatotic hepatocytes was found when fatty cells were incubated for 5.5 hours or longer, compared to nonsteatotic control hepatocytes. APAP did not cause significant changes in LDH activity of both lean and steatotic hepatocytes cultured for 5.5 and 8 hours in comparison to appropriate control. Between 8 and 18 hours, there was an increase in LDH activity in medium of non-fatty hepatocytes treated with 3.75 and $5 \mathrm{mM}$ APAP and more dramatic elevation of $\mathrm{LDH}$ activity in cultures of steatotic hepatocytes incubated with any tested concentration of APAP [even $1 \mathrm{mM}$ APAP $(\mathrm{p}<0.01)$ caused significantly higher activity of LDH]. Results of LDH activity were confirmed by measurement of LDH leakage at 24 hours (Table 1).

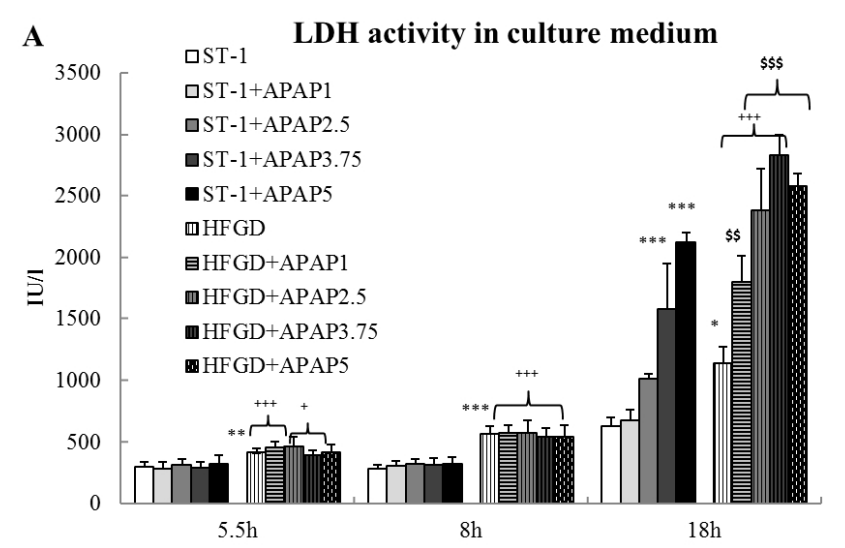

B
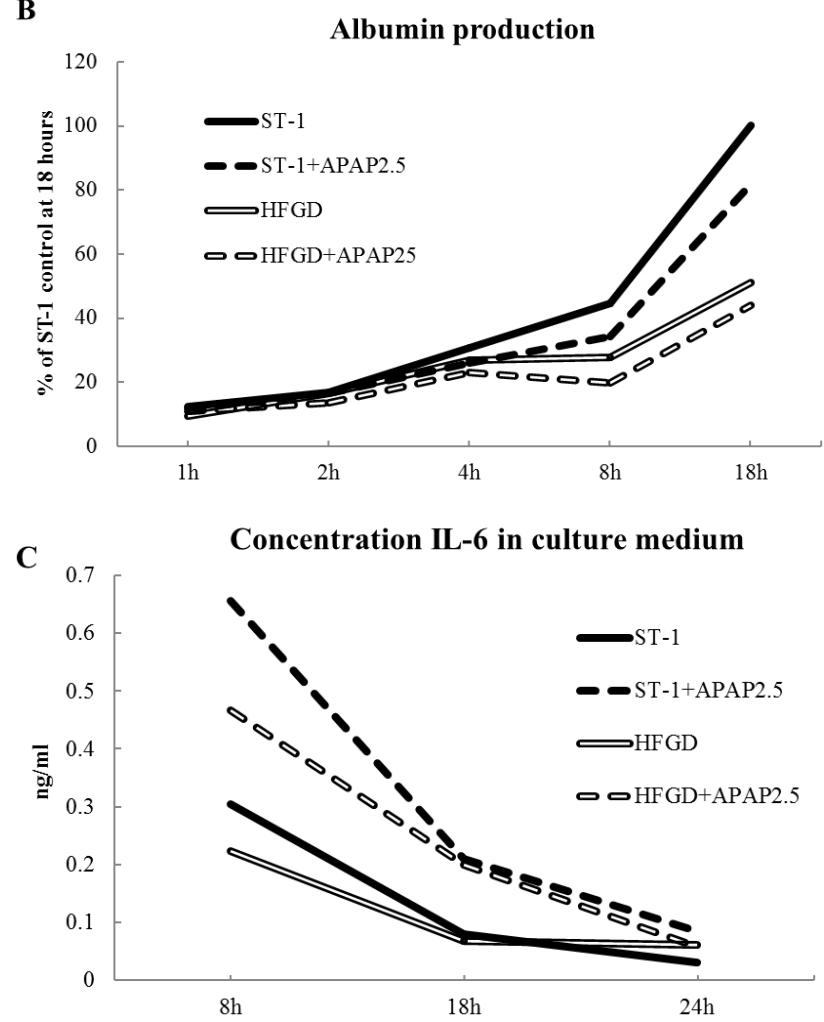

Fig. 1. Time course of LDH activity in culture media (A), albumin production (B) and IL-6 production by hepatocytes $(\mathbf{C})$ in primary cultures treated with APAP $(n=3 ;$ SD and statistical significance are not shown in $\mathrm{B}$ and $\mathrm{C}$; $* \mathrm{p}<0.05, * * \mathrm{p}<0.01, * * * \mathrm{p}<0.001$ vs. control ST-1; $\$ p<0.01, \$ \$ \$ p<0.001$ vs. control HFGD; $+p<0.05$, $+++p<0.001$ vs. ST-1+APAP of appropriate concentration). 


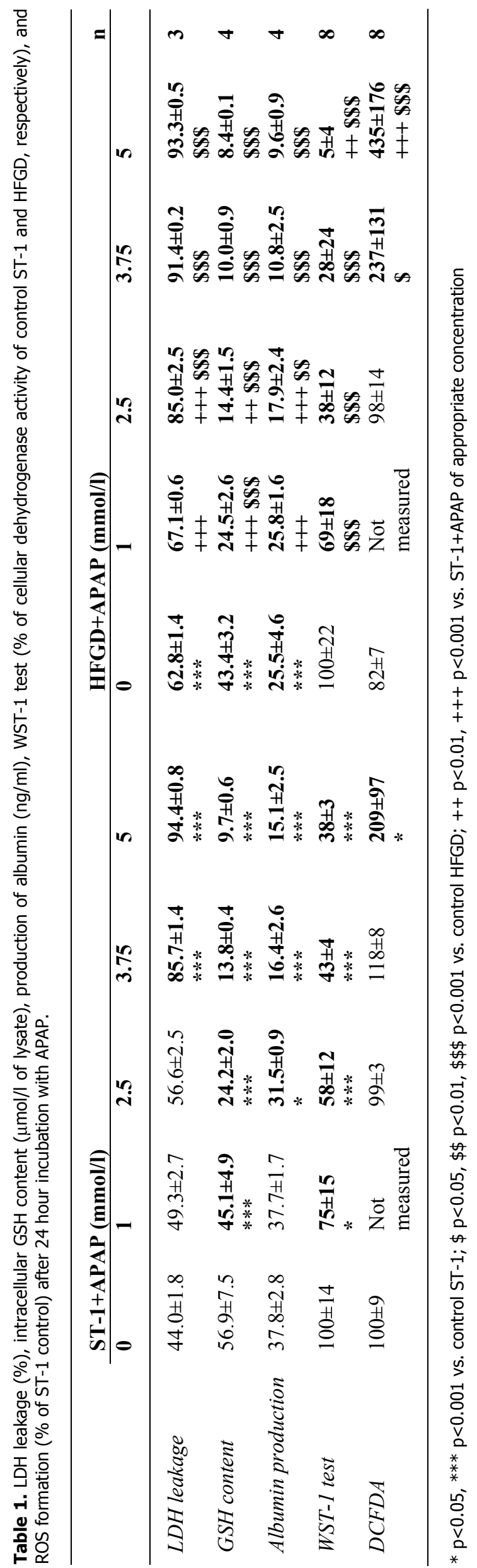



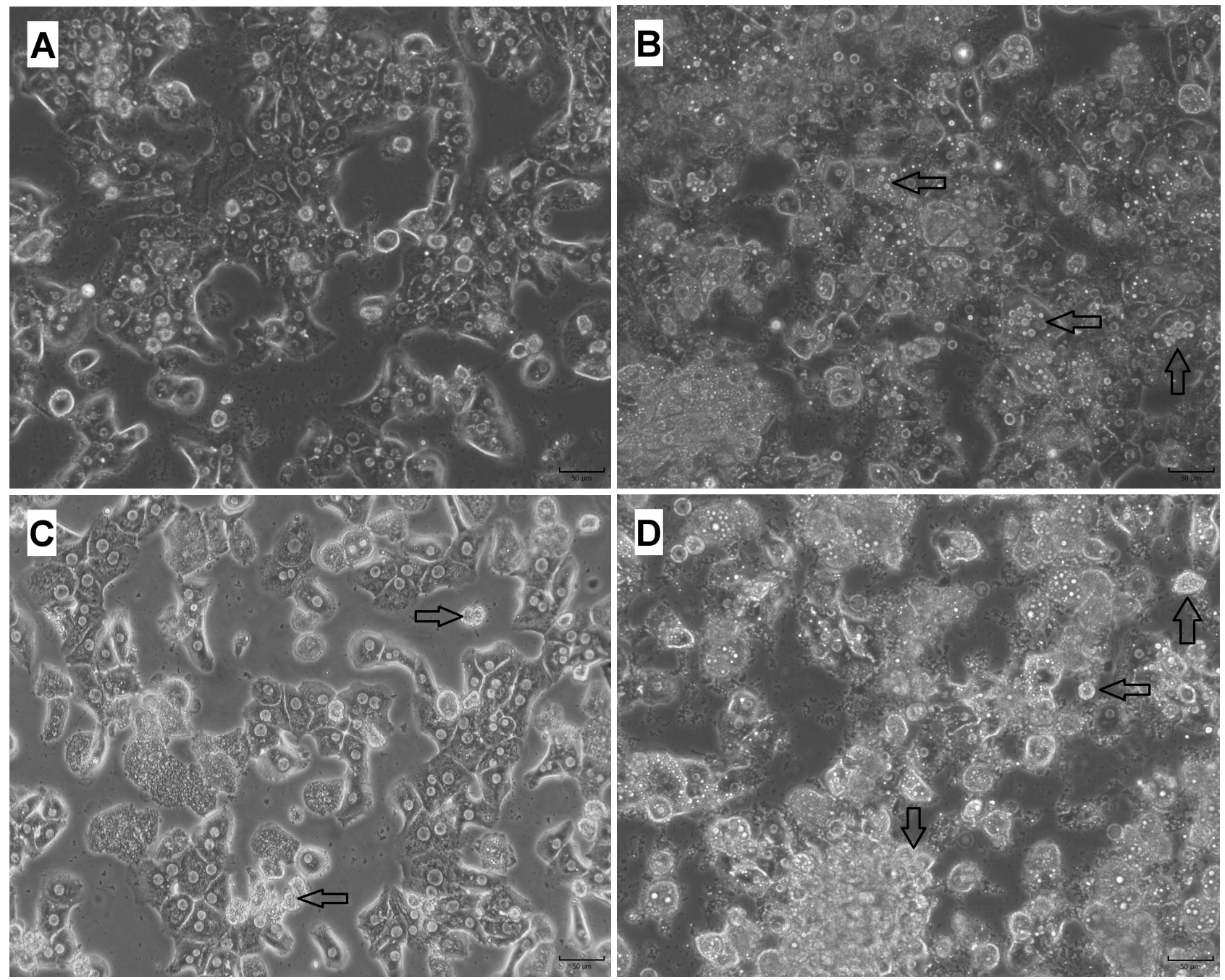

Fig. 2. Microphotographs of intact lean (A) and fatty hepatocytes (B; arrows point steatotic hepatocytes), and non-steatotic (C; arrows point detached dead hepatocytes) and steatotic (D; arrows point detached dead hepatocytes) rat hepatocytes incubated with $2.5 \mathrm{mM}$ APAP for 24 hours (phase contrast, magnification 200x, bar $50 \mu \mathrm{m}$ ).

Activities of cellular dehydrogenases (WST-1 test) in cell culture at 24 hours are shown in Table 1. Because of generally lower dehydrogenase activities of steatotic cells compared to non-fatty cells $(\mathrm{p}<0.001$, data not shown), results of WST-1 test are expressed in percentages where $100 \%$ was set to dehydrogenase activities of nonsteatotic and fatty control cultures for APAP-treated lean and steatotic hepatocytes, respectively. Cell viability, measured by WST-1 test, was affected by APAP administration in a dose dependent manner. Significantly lower relative dehydrogenase activity was observed in steatotic cells after $24 \mathrm{~h}$ incubation only with $5 \mathrm{mM}$ APAP.

Figure 1B depicts time course of albumin production by primary hepatocyte cultures. We found that albumin production by control fatty hepatocytes is significantly decreased already after 8-hour cultivation compared to control lean cells. Incubation with APAP
( $2.5 \mathrm{mmol} / \mathrm{l})$ for at least 8 hours induced reduction of albumin synthesis by both non-steatotic $(\mathrm{p}<0.01)$ and steatotic $(p<0.05)$ hepatocytes. Results of albumin concentrations in culture media at 24 hours confirm lower production of albumin by steatotic hepatocytes and minimal concentration of APAP $(2.5 \mathrm{mmol} / \mathrm{l})$ for a decrease in functional capacity of both kinds of hepatocytes (Table 1).

Intracellular content of GSH was measured only at 24 hours (Table 1). Intact steatotic hepatocytes contained lower amount of GSH vs. lean cells. Already the lowest tested concentration of APAP ( $1 \mathrm{mmol} / \mathrm{l})$ caused reduction of intracellular GSH; decrease in GSH induced by 1 and $2.5 \mathrm{mM}$ APAP was more pronounced in fatty hepatocytes than in non-fatty cells.

We also evaluated ROS generation in hepatocyte cultures at 24 hours (Table 1). There was no difference in ROS formation between control nonsteatotic and fatty 
hepatocytes. In non-fatty cells, only the highest tested concentration of APAP induced higher ROS production (approx. 2-fold increase) whereas steatotic hepatocytes exerted higher formation of ROS when exposed to APAP at concentration of 3.75 and $5 \mathrm{mmol} / 1$ (approx. 2-fold and 4-fold increase, respectively).

Figure 1C shows concentration of IL-6 in culture media between 8 and 24 hours. We did not observe any differences in levels of IL- 6 between control nonsteatotic and control fatty hepatocytes in tested time intervals. Incubation with APAP at concentration of $2.5 \mathrm{mmol} / \mathrm{l}$ for 8 hours caused significantly higher production of IL- 6 by lean $(p<0.001)$ and fatty $(p<0.001)$ hepatocytes, compared to appropriate controls. IL- 6 concentration in the medium of APAP-treated nonsteatotic cells at 8 hours was even higher than in the medium of fatty hepatocytes $(p<0.01)$. We did not find differences in IL- 6 production of APAP-treated cells in subsequent time intervals. TNF alpha production showed similar trends as IL-6 (data not shown).

Hepatocytes isolated from rat liver of HFGD fed animals exerted microvesicular steatosis (Fig. 2B) in comparison with intact lean cells (Fig. 2A). Nonsteatotic hepatocytes incubated with $2.5 \mathrm{mM}$ APAP (Fig. 2C) for 24 hours showed cellular damage and death of some hepatocytes (detachment of cells from collagen, spherical shape and plasma membrane blebbing, highly granular cytoplasm, loss of nuclear visibility). Steatotic hepatocytes treated with APAP (Fig. 2D) showed more pronounced injury and increased incidence of cell death (most of hepatocytes are detached and of spherical shape without visible nucleus).

\section{Discussion}

APAP is one of mostly used analgesics and antipyretics worldwide and APAP poisoning is the leading cause of acute liver failure in the USA (Lee 2003). NAFLD is the most common chronic hepatic affection in the western countries and simple "benign" steatosis is the main form of NAFLD. The question may arise whether even simple fatty liver can predispose the liver to increased sensitivity to the hepatotoxic action of various compounds including APAP. Although our research group has already showed that steatotic rat liver exerts higher susceptibility to hepatotoxicity of APAP (Kučera et al. 2012) and other hepatotoxins in vivo (Kučera et al. 2011b), we did not find the detailed mechanism of increased toxic action of APAP in the liver affected by NAFLD. Primary cultures of hepatocytes may be the appropriate in vitro model for studying of particular mechanisms of APAP toxicity. The aim of our work was to compare sensitivity of lean hepatocytes and hepatocytes isolated from simply fatty liver in primary culture to acute hepatotoxic effect of APAP and possibly find a reason or reasons for this increased susceptibility of fatty hepatocytes to APAP.

In APAP overdose, a significant amount of APAP is biotransformed by cytochrome p450 oxidase enzyme system to NAPQI, which is detoxified by intracellular GSH. After GSH depletion, NAPQI covalently binds to critical cellular proteins, which finally leads to hepatocellular damage. Experimental depression of cellular GSH level by administration of various compounds before APAP addition increased toxicity of APAP in mice (James et al. 1993). Similarly, intracellular content of GSH may be reduced in the liver affected by NAFLD by changes in cellular homeostasis (Videla et al. 2004). Our results showed significant reduction of GSH in control fatty hepatocytes by $24 \%$ compared to intact lean cells. Incubation with the lowest tested concentration of APAP $(1 \mathrm{mmol} / \mathrm{l})$ caused more pronounced decrease in GSH in fatty hepatocytes (by $44 \%$ of control steatotic hepatocytes) than in lean cells (by $21 \%$ of control nonsteatotic hepatocytes). Decrease in GSH to approximately to $25 \%$ of level of control nonsteatotic cells, induced by 3.75 and $2.5 \mathrm{mM}$ concentration of APAP in lean and fatty hepatocytes, respectively, caused similar LDH leakage in both cultures. When amount of GSH dropped to less than $20 \%$ of control lean hepatocytes at 24 hours, all the cells were dead (data not presented) and LDH leakage exceeded $90 \%$. This percentage of GSH decline corresponds well with results of Mitchell (Mitchell et al. 1973) who found that centrilobular necrosis of the liver overdosed by APAP occurs when GSH levels decreased to $20 \%$ of normal GSH levels. Lower amount of GSH in intact fatty liver may be caused by elevated production of ROS as a result of enhanced mitochondrial and peroxisomal $\beta$-oxidation and microsomal $\omega$-oxidation and unchanged expressions of glutathione synthase (Kohjima et al. 2007) and especially catalytic subunit of rate limiting enzyme of GSH synthesis glutamate-cysteine ligase (Lickteig et al. 2007). Oxidative stress is considered to be an important factor not only in the development of NAFLD but also in the APAP toxicity. Although we did not find an increase in formation of ROS in control fatty hepatocytes at 24 hours, incubation with 3.75 and $5 \mathrm{mM}$ APAP caused 
more than 2-fold and 4-fold increase in ROS, respectively. In contrast in lean hepatocytes, only the highest dosage of APAP ( $5 \mathrm{mM})$ induced significant 2fold elevation of ROS. These results are in a good agreement with our previous findings (Roušar et al. 2009). GSH is widely used as a marker of oxidative stress. Increased production of ROS was found only when GSH levels were less than $20 \%$ of GSH content in control lean hepatocytes. Imbalance of hepatic redox status predisposes fatty liver not only to increased sensitivity to various toxins but also to fibrogenesis (Phung et al. 2009). Reduction of intracellular GSH in intact fatty hepatocytes may explain toxic action of APAP in "nontoxic dosage" in vitro.

Albumin production and urea synthesis are widely used tests of hepatocyte function in vitro. We measured concentration of albumin in culture medium in time and at 24 hours of incubation. Steatotic hepatocytes exerted significantly lower proteosynthetic capacity from 8 hours and at 24 hours, fatty cultures synthetized only $68 \%$ of albumin production of control nonsteatotic cells. These results are inconsistent with findings of Charlton (Charlton et al. 2002) who did not observe decreased albumin synthesis in patients with non-alcoholic steatohepatitis but are in agreement with findings of other authors. De Fao et al. (1991) reported that insulin deficiency (often matched with primary NAFLD) decreases albumin synthesis in rats and Jefferson et al. (1983) found that withdrawal of insulin therapy in the diabetic rats resulted in marked reduction in albumin synthesis. Absolute production of albumin was decreased by fatty hepatocytes when exposed to APAP, but relative decrease ( $\%$ of appropriate controls) of albumin concentrations in culture medium of APAP-treated hepatocytes were proportionally similar in lean and steatotic cells. Dramatic increase in LDH release from APAP-treated cells occurred between 8 and 18 hours of incubation but surprisingly was not followed by proportional decrease in albumin production at this time interval.

The complex role of inflammatory cells and proinflammatory cytokines in the mechanism of APAP toxicity has been widely studied. Kupffer cells in the liver exposed to APAP become activated and subsequently trigger inflammatory response leading to recruitment of inflammatory cells to the liver (Hinson et al. 2010). In vivo, TNF- $\alpha$ and IL-6 initiate liver regeneration and depletion of IL- 6 may result in increased sensitivity to acetaminophen (Masubuchi et al. 2003). Cytokine imbalance is another important factor in the development of NAFLD (Braunersreuther et al. 2012). Despite that, we did not find any difference in IL-6 production in control lean and fatty hepatocytes. Kupffer cells are the major source of hepatic IL-6 in the liver. In vivo, hepatocytes are about $60 \%$ of hepatic cells and non-parenchymal cells (such as sinusoidal endothelial cells, Kupffer cells, hepatic stellate cells, and intrahepatic lymphocytes) comprise remaining $40 \%$ (Kmieć 2001). Kupffer cells account for about $15 \%$ of all hepatic cells (Decker 1990). In contrast to situation in vivo, liver cells isolated by twostep collagenase perfusion are from more than $95 \%$ hepatocytes and only less than $5 \%$ non-parenchymal cells (Guillouzo 1998). Thus primary cultures of hepatocytes contain only small amount of Kupffer cells. APAP induced even higher secretion of IL- 6 by lean hepatocytes than fatty cells at 8 hours. This higher IL-6 production can be beneficial for survival of nonsteatotic hepatocytes since IL-6 is known that may protect the liver from injury by up-regulation of the hepatic expression of several cytoprotective heat shock proteins (Masubuchi et al. 2003).

In conclusion, our study showed that primary cultures of fatty hepatocytes isolated from rat liver affected by NAFLD exert higher susceptibility to acute hepatotoxicity of APAP than nonsteatotic hepatocytes. One of factors that may increase sensitivity of steatotic hepatocytes to APAP in vitro is lower content of GSH in intact steatotic hepatocytes and more pronounced APAPinduced reduction of intracellular concentration of GSH. Results of this study confirmed our previous findings of lower resistance of the liver affected by NAFLD to toxic action of APAP in vivo (Kučera et al. 2012).

\section{Conflict of Interest}

There is no conflict of interest.

\section{Acknowledgements}

This study was supported by the programme PRVOUK P37/02.
Abbreviations
APAP - acetaminophen; GSH - reduced form of glutathione; IL-6 - interleukin 6; LDH - lactate dehydrogenase; NAFLD - non-alcoholic fatty liver disease; NAPQI - N-acetyl-p-benzoquinone imine; ROS - reactive oxygen species. 


\section{References}

BAJT ML, KNIGHT TR, LEMASTERS JJ, JAESCHKE H: Acetaminophen-induced oxidant stress and cell injury in cultured mouse hepatocytes: protection by N-acetyl cysteine. Toxicol Sci 80: 343-349, 2004.

BEDOGNI G, MIGLIOLI L, MASUTTI F, TIRIBELLI C, MARCHESINI G, BELLENTANI S: Prevalence of and risk factors for nonalcoholic fatty liver disease: the Dionysos nutrition and liver study. Hepatology 42: 44-52, 2005.

BERRY MN, EDWARDS AM, BARRITT GJ: High-yield preparation of isolated hepatocytes from rat liver. In: Isolated Hepatocytes Preparation, Properties and Application. BURDON RH, VAN KNIPPENBERG PH (eds), Elsevier, New York, 1991, pp 15-81.

BRAUNERSREUTHER V, VIVIANI GL, MACH F, MONTECUCCO F: Role of cytokines and chemokines in nonalcoholic fatty liver disease. World J Gastroenterol 18: 727-735, 2012.

CHARLTON M, SREEKUMAR R, RASMUSSEN D, LINDOR K, NAIR KS: Apolipoprotein synthesis in nonalcoholic steatohepatitis. Hepatology 35: 898-904, 2002.

DAHLIN DC, MIWA GT, LU AY, NELSON SD: N-acetyl-p-benzoquinone imine: a cytochrome P-450-mediated oxidation product of acetaminophen. Proc Natl Acad Sci U S A 81: 1327-1331, 1984.

DE FEO P, GAISANO MG, HAYMOND MW: Differential effects of insulin deficiency on albumin and fibrinogen synthesis in humans. J Clin Invest 88: 833-840, 1991.

DECKER K: Biologically active products of stimulated liver macrophages (Kupffer cells). Eur J Biochem 192: 245261, 1990.

GAMBINO R, MUSSO G, CASSADER M: Redox balance in the pathogenesis of nonalcoholic fatty liver disease: mechanisms and therapeutic opportunities. Antioxid Redox Signal 15: 1325-1365, 2011.

GUILLOUZO A: Liver cell models in in vitro toxicology. Environ Health Perspect 106 (Suppl 2): 511-532, 1998.

HINSON JA, ROBERTS DW, JAMES LP: Mechanisms of acetaminophen-induced liver necrosis. Handb Exp Pharmacol 196: 369-405, 2010.

JAMES RC, HARBISON RD, ROBERTS SM: Phenylpropanolamine potentiation of acetaminophen-induced hepatotoxicity: evidence for a glutathione-dependent mechanism. Toxicol Appl Pharmacol 118: 159-168, 1993.

JEFFERSON LS, LIAO WS, PEAVY DE, MILLER TB, APPEL MC, TAYLOR JM: Diabetes-induced alterations in liver protein synthesis. Changes in the relative abundance of mRNAs for albumin and other plasma proteins. J Biol Chem 258: 1369-1375, 1983.

JU C, REILLY TP, BOURDI M, RADONOVICH MF, BRADY JN, GEORGE JW, POHL LR: Protective role of Kupffer cells in acetaminophen-induced hepatic injury in mice. Chem Res Toxicol 15: 1504-1513, 2002.

KMIEĆ Z: Cooperation of liver cells in health and disease. Adv Anat Embryol Cell Biol 161: 1-151, 2001.

KOHJIMA M, ENJOJI M, HIGUCHI N, KATO M, KOTOH K, YOSHIMOTO T, FUJINO T, YADA M, YADA R, HARADA N, TAKAYANAGI R, NAKAMUTA M: Re-evaluation of fatty acid metabolism-related gene expression in nonalcoholic fatty liver disease. Int J Mol Med 20: 351-358, 2007.

KON K, KIM JS, JAESCHKE H, LEMASTERS JJ: Mitochondrial permeability transition in acetaminophen-induced necrosis and apoptosis of cultured mouse hepatocytes. Hepatology 40: 1170-1179, 2004.

KUČERA O, GARNOL T, LOTKOVÁ H, STAŇKOVÁ P, MAZUROVÁ Y, HROCH M, BOLEHOVSKÁ R, ROUŠAR T, ČERVINKOVÁ Z: The effect of rat strain, diet composition and feeding period on the development of a nutritional model of non-alcoholic fatty liver disease in rats. Physiol Res 60: 317-328, $2011 \mathrm{a}$.

KUČERA O, LOTKOVÁ H, STAŇKOVÁ P, PODHOLA M, ROUŠAR T, MEZERA V, ČERVINKOVÁ Z: Is rat liver affected by non-alcoholic steatosis more susceptible to the acute toxic effect of thioacetamide? Int $J$ Exp Pathol 92: 281-289, 2011b.

KUČERA O, ROUŠAR T, STAŇKOVÁ P, HAŇÁČKOVÁ L, LOTKOVÁ H, PODHOLA M, ČERVINKOVÁ Z: Susceptibility of rat non-alcoholic fatty liver to the acute toxic effect of acetaminophen. $J$ Gastroenterol Hepatol 27: 323-330, 2012.

LEE WM: Acute liver failure in the United States. Semin Liver Dis 23: 217-226, 2003.

LICKTEIG AJ, FISHER CD, AUGUSTINE LM, CHERRINGTON NJ: Genes of the antioxidant response undergo upregulation in a rodent model of nonalcoholic steatohepatitis. J Biochem Mol Toxicol 21: 216-220, 2007. 
LIEBER CS, LEO MA, MAK KM, XU Y, CAO Q, REN C, PONOMARENKO A, DECARLI LM: Model of nonalcoholic steatohepatitis. Am J Clin Nutr 79: 502-509, 2004.

LOTKOVÁ H, KUČERA O, ROUŠAR T, ENDLICHER R, KŘIVÁKOVÁ P, GARNOL T, ČERVINKOVÁ Z: Effect of S-adenosylmethionine on Acetaminophen-induced Toxic Injury of Rat Hepatocytes in vitro. Acta Vet Brno 78: 603-613, 2009.

MASUBUCHI Y, BOURDI M, REILLY TP, GRAF ML, GEORGE JW, POHL LR: Role of interleukin-6 in hepatic heat shock protein expression and protection against acetaminophen-induced liver disease. Biochem Biophys Res Commun 304: 207-212, 2003.

MITCHELL JR, JOLLOW DJ, POTTER WZ, GILLETTE JR, BRODIE BB: Acetaminophen-induced hepatic necrosis. IV. Protective role of glutathione. J Pharmacol Exp Ther 187: 211-217, 1973.

ORELLANA M, RODRIGO R, VARELA N, ARAYA J, PONIACHIK J, CSENDES A, SMOK G, VIDELA LA: Relationship between in vivo chlorzoxazone hydroxylation, hepatic cytochrome P450 2E1 content and liver injury in obese non-alcoholic fatty liver disease patients. Hepatol Res 34: 57-63, 2006.

PHUNG N, PERA N, FARRELL G, LECLERCQ I, HOU JY, GEORGE J: Pro-oxidant-mediated hepatic fibrosis and effects of antioxidant intervention in murine dietary steatohepatitis. Int J Mol Med 24: 171-180, 2009.

ROLLINS DE, BUCKPITT AR: Liver cytosol catalyzed conjugation of reduced glutathione with a reactive metabolite of acetaminophen. Toxicol Appl Pharmacol 47: 331-339, 1979.

ROUŠAR T, KUČERA O, KŘIVÁKOVÁ P, LOTKOVÁ H, KANĎÁR R, MUŽÁKOVÁ V, ČERVINKOVÁ Z: Evaluation of oxidative status in acetaminophen treated rat hepatocytes in culture. Physiol Res 58: 239-246, 2009.

ROUŠAR T, PAŘÍK P, KUČERA O, BARTOŠ M, ČERVINKOVÁ Z: Glutathione reductase is inhibited by acetaminophen-glutathione conjugate in vitro. Physiol Res 59: 225-232, 2010.

ROUŠAR T, KUČERA O, LOTKOVÁ H, ČERVINKOVÁ Z: Assessment of reduced glutathione: comparison of an optimized fluorometric assay with enzymatic recycling method. Anal Biochem 423: 236-240, 2012.

VENDEMIALE G, GRATTAGLIANO I, ALTOMARE E, TURTURRO N, GUERRIERI F: Effect of acetaminophen administration on hepatic glutathione compartmentation and mitochondrial energy metabolism in the rat. Biochem Pharmacol 52: 1147-1154, 1996.

VENDEMIALE G, GRATTAGLIANO I, CARACENI P, CARACCIO G, DOMENICALI M, DALl'AGATA M, TREVISANI F, GUERRIERI F, BERNARDI M, ALTOMARE E: Mitochondrial oxidative injury and energy metabolism alteration in rat fatty liver: effect of the nutritional status. Hepatology 33: 808-815, 2001.

VERNON G, BARANOVA A, YOUNOSSI ZM: Systematic review: the epidemiology and natural history of nonalcoholic fatty liver disease and non-alcoholic steatohepatitis in adults. Aliment Pharmacol Ther 34: 274-285, 2011.

VIDELA LA, RODRIGO R, ORELLANA M, FERNANDEZ V, TAPIA G, QUIÑONES L, VARELA N, CONTRERAS J, LAZARTE R, CSENDES A, ROJAS J, MALUENDA F, BURDILES P, DIAZ JC, SMOK G, THIELEMANN L, PONIACHIK J: Oxidative stress-related parameters in the liver of non-alcoholic fatty liver disease patients. Clin Sci (Lond) 106: 261-268, 2004. 